\title{
CLARREO Approach for Reference Intercalibration of Reflected Solar Sensors: On-Orbit Data Matching and Sampling
}

\author{
Carlos M. Roithmayr, Constantine Lukashin, Paul W. Speth, Greg Kopp, \\ Kurt Thome, Bruce A. Wielicki, and David F. Young
}

\begin{abstract}
The implementation of the Climate Absolute Radiance and Refractivity Observatory (CLARREO) mission was recommended by the National Research Council in 2007 to provide an on-orbit intercalibration standard with accuracy of $0.3 \%$ $(k=2)$ for relevant Earth observing sensors. The goal of reference intercalibration, as established in the Decadal Survey, is to enable rigorous high-accuracy observations of critical climate change parameters, including reflected broadband radiation [Clouds and Earth's Radiant Energy System (CERES)], cloud properties [Visible Infrared Imaging Radiometer Suite (VIIRS)], and changes in surface albedo, including snow and ice albedo feedback. In this paper, we describe the CLARREO approach for performing intercalibration on orbit in the reflected solar (RS) wavelength domain. It is based on providing highly accurate spectral reflectance and reflected radiance measurements from the CLARREO Reflected Solar Spectrometer (RSS) to establish an on-orbit reference for existing sensors, namely, CERES and VIIRS on Joint Polar Satellite System satellites, Advanced Very High Resolution Radiometer and follow-on imagers on MetOp, Landsat imagers, and imagers on geostationary platforms. One of two fundamental CLARREO mission goals is to provide sufficient sampling of high-accuracy observations that are matched in time, space, and viewing angles with measurements made by existing instruments, to a degree that overcomes the random error sources from imperfect data matching and instrument noise. The data matching is achieved through CLARREO RSS pointing operations on orbit that align its line of sight with the intercalibrated sensor. These operations must be planned in advance; therefore, intercalibration events must be predicted by orbital modeling. If two competing opportunities are identified, one target sensor must be given priority over the other. The intercalibration method is to monitor changes in targeted sensor response function parameters: effective offset, gain, nonlinearity, optics spectral response, and sensitivity to polarization. In this paper, we use existing satellite data and orbital simulation methods to determine mission requirements for CLARREO, its instrument pointing ability, methodology, and needed intercalibration sampling and data matching for accurate intercalibration of $\mathrm{RS}$ radiation sensors on orbit.
\end{abstract}

Manuscript received February 22, 2013; revised August 8, 2013 and November 21, 2013; accepted January 18, 2014. Date of publication March 3, 2014; date of current version May 22, 2014. This work was supported by the NASA CLARREO project.

C. M. Roithmayr, C. Lukashin, B. A. Wielicki, and D. F. Young are with NASA Langley Research Center, Hampton, VA 23681 USA (e-mail: constantine.lukashin@nasa.gov).

P. W. Speth is with NASA Langley Research Center, Hampton, VA 23681 USA and also with George Washington University, Washington, DC 20052 USA.

G. Kopp is with the Laboratory for Atmospheric and Space Physics, University of Colorado, Boulder, CO 80303 USA.

K. Thome is with NASA Goddard Space Flight Center, Greenbelt, MD 20771 USA.

Digital Object Identifier 10.1109/TGRS.2014.2302397
We conclude that with the CLARREO RSS in a polar $90^{\circ}$ inclination orbit at a $609-\mathrm{km}$ altitude, estimated intercalibration sampling will limit the uncertainty contribution from data matching noise to $0.3 \%(k=2)$ over the climate autocorrelation time period. The developed orbital modeling and intercalibration event prediction will serve as a framework for future mission operations.

Index Terms-Data sampling, intercalibration, orbital simulation, radiometry.

\section{INTRODUCTION}

$\mathbf{T}$ HE implementation of the Climate Absolute Radiance and Refractivity Observatory (CLARREO) mission was recommended by the National Research Council in 2007 [1] as a means of initiating a benchmark climate record of unprecedented accuracy and providing an on-orbit calibration standard, traceable to Systeme International (SI), for relevant Earth observing sensors. The CLARREO absolute accuracy goals are set to allow the climate record to survive gaps, unlike current satellite records where overlap is critical and levels of calibration stability are difficult to establish [17]. The CLARREO observations include high-spectral-resolution solar reflectance and infrared radiance, along with Global Navigational Satellite System radio occultation observations [26]. The goal of the mission is to initiate an unprecedented high-accuracy record of climate change. These measurements address the need to make rigorous observations of climate change on decadal time scales and to use these observations as the most critical method to determine the accuracy of climate change projections that become the foundation for informed decisions on mitigation and adaptation policies. The CLARREO project is currently in a preformulation phase, and in this study, we assume that its Reflected Solar Spectrometer (RSS) will measure the reflected solar (RS) radiance spectrum with SI-traceable accuracy ${ }^{1}$ of $0.3 \%(k=2)$, contiguously from 320 to $2300 \mathrm{~nm}$ with $4-\mathrm{nm}$ spectral sampling. This accuracy level is determined by the projected decadal changes due to anthropogenic forcing along with the background natural variability above which such changes must be detected [26]. The combination of high spatial and spectral resolution and the designed ability to point the CLARREO RSS enables the use of CLARREO observations as reference intercalibration for existing spaceborne sensors

\footnotetext{
${ }^{1}$ We use $k$ instead of $\sigma$ to establish a more rigorous tie between the climate science and metrology research communities. In the case of a Gaussian distribution, $k=2$ is the same confidence level as for $2 \sigma$.
} 
relevant to climate change observations. The CLARREO Science Team is collaborating with an independent effort led by U.K., called Traceable Radiometry Underpinning Terrestrialand Helio- Studies (TRUTHS) [7], which proposes a different instrument technology. That mission could provide critical independent verification of CLARREO accuracy similar to the verification required by independent metrology laboratories for international standards.

Intercalibration of sensors in orbit is a very important ongoing effort in the remote sensing community. The Global Space-based Inter-Calibration System, which is initiated by the World Meteorological Organization and the Coordination Group for Meteorological Satellites in 2005, is an international collaboration focused on intercalibration of current low Earth orbit (LEO) and geostationary Earth orbit (GEO) weather satellites using a variety of methods that include vicarious calibration, Earth targets, and simultaneous nadir overpasses (SNOs) [8]. Another example is the intercalibration of the Clouds and the Earth's Radiant Energy System (CERES) and Geostationary Earth Radiation Budget (GERB) instruments that was performed by both teams [3], [21]. Recently, Doelling et al. [5] have made progress using deep convective clouds (DCC) as invariant targets for stability of calibration. A group at NASA Langley Research Center (LaRC) demonstrated intercalibration of geostationary imagers using SCanning Imaging Absorption spectroMeter for Atmospheric CartograpHY (SCIAMACHY) spectral observations [6]. However, because the current space missions are not designed to perform special operations for intercalibration on orbit, there are several serious limitations to the use of these results to study decadal climate change. First, they lack the accuracy required for detection of climate trends on a decadal time scale. The best existing imaging instruments, such as the Moderate Resolution Imaging Spectroradiometer (MODIS), are estimated to be accurate to about $2 \%-3 \%$ [23], [28]-[30]. Second, use of surface targets for vicarious instrument calibration is limited by required atmospheric corrections and changing surface conditions-rainfall, dust, vegetation change, ice and snow surface structure that changes with wind speed and direction, aging of snow and ice grains, and contamination with absorbing soot aerosols. Third, all of the narrowband RS sensors are sensitive to polarization of reflected light, but to date, this effect has been accounted for only in the ocean color data products [14].

In this paper, we define the term reference intercalibration (RI) as the calibration of a sensor with the CLARREO RSS on-orbit measurements, which are SI-traceable with accuracy of $0.3 \%(k=2)$ of the mean Earth's albedo of 0.3 [26]. We describe the CLARREO approach and show the advantages of a mission specifically designed to perform on-orbit intercalibration of existing sensors in low-Earth and geostationary orbits, for both broadband and narrowband radiometers.

The remainder of this paper is organized as follows. In Section II, we describe the primary goals of CLARREO RSS RI and define a methodology for obtaining the data sampling necessary to reduce matching noise and achieve the required intercalibration accuracy. In Section III, we show the results of operational modeling for a one-year time period: We examine CLARREO RSS intercalibration of cross-track instruments on
TABLE I

MAJOR REQUIREMENTS FOR THE CLARREO RSS INSTRUMENT

\begin{tabular}{|l|l|}
\hline Parameter & Instrument Requirement \\
\hline \hline Accuracy & $0.3 \%(k=2)$ in broadband reflectance \\
\hline Spectral Range & $320 \mathrm{~nm}$ to $2300 \mathrm{~nm}$ \\
\hline Spectral Sampling & $4 \mathrm{~nm}$ \\
\hline Instantaneous Field-of-View & $0.5 \mathrm{~km} \times 0.5 \mathrm{~km}$ \\
\hline Swath Width & $100 \mathrm{~km}$ \\
\hline Signal-to-Noise Ratio & $>33\left(\right.$ for mean 0.3 reflectance at SZA $\left.=75^{\circ}\right)$ \\
\hline
\end{tabular}

the Joint Polar Satellite System (JPSS) satellite [e.g., CERES and Visible Infrared Imager Radiometer Suite (VIIRS)] in Section III-A and of GEO-based imagers [e.g., Geostationary Operational Environmental Satellite R-Series (GOES-R) Advanced Baseline Imager] in Section III-B. In Section IV, we present numerical results of intercalibration data sampling estimates and compare these with mission accuracy requirements. In Section V, we discuss the current results and outline the intercalibration methodology. Finally, in Section VI, we summarize the CLARREO RSS mission requirements and options for improving the intercalibration data sampling.

\section{CLARREO RI GoAls AND Methodology}

CLARREO is being designed to be the first "metrology lab" orbiting the Earth, providing a reference to international standards at the accuracy needed for detecting climate change. Here, we review the requirements for the RSS and its performance and mission objectives for intercalibration relevant to Earth observing radiometric sensors.

\section{A. CLARREO RSS}

The intercalibration methodology cannot be separately viewed from the CLARREO mission requirements and instrument features. The sensor design is based on the required derivation of an at-sensor reflectance over the spectral range from 320 to $2300 \mathrm{~nm}$ with 4-nm spectral sampling, with $0.5-\mathrm{km}$ ground field of view (GFOV) and a 100-km swath width. That is, measurements of radiance while viewing Earth's surface will be converted to a reflectance through ratios to solar- and lunarbased measurements [26]. The measurement signal will vary by factors of 2-10 because it is functionally dependent on solar zenith angle (SZA), wavelength, atmospheric gas absorption, which changes with altitude and wavelength, and scene type, which ranges from dark (clear-sky ocean) to bright (DCC). The RSS instrument must be designed to account for these effects and to include a calibration approach that allows accurate retrieval of the reflectance in the mid-visible wavelength range, traceable to SI standards at a level better than $0.3 \%$ $(k=2)$. Such required accuracy provides a data set that, when collected globally, reduces sampling biases for climatologically significant spatial and temporal averages over annual means. The major instrument requirements for the CLARREO RSS are summarized in Table I. The instrument spectral range and spectral sampling requirements are motivated by intercalibration of the broadband (CERES) and narrowband (VIIRS) radiometers, respectively. The spatial sampling with $0.5-\mathrm{km}$ GFOV is for achieving a quality cloud masking, and spatial coverage is motivated by the CLARREO RSS "benchmark" global sampling at nadir. 
The primary data product from the RSS instrument is spectral reflectance. The current operational plan for the RSS instrument is to determine the ratio of the output of the instrument while viewing an Earth scene to that of the instrument while viewing the Sun. Taking into account the geometry differences between a radiance measurement (while viewing the Earth scene) and an irradiance measurement (the solar measurement) permits the retrieval of a directional-hemispheric reflectance. Thus, the RSS sensor will function like a band-ratioing radiometer. The instrument is based on an Offner imaging spectrometer design, which is capable of limiting spectral smile on the focal plane. The instrument will operate as a push-broom imager with a reliance on heritage hardware, reduction of sensor complexity, and solar- and lunar-source-based calibration.

In order to observe both Earth's reflected radiance and solar irradiance (to have both signals in the same dynamic range), the RSS instrument must be able to reduce the incident solar irradiance to a level comparable with the Earth-viewing radiance, approximately a factor of 50000 . The attenuator approaches being evaluated include a single pinhole aperture, neutral density filters, and a collection of pinhole apertures or combinations of these three. The reason that three attenuator approaches are currently under study is that an additional goal of CLARREO is to rely on multiple and independent calibration approaches. The attenuators require extremely careful evaluation during ground testing and are also a source of uncertainty on orbit if the attenuators degrade in some fashion. Evaluation of the attenuators on orbit takes place through coordinated views of the Sun and the Moon. The brightness of the Moon is low enough to permit measurements without the attenuators in place, allowing the coupled lunar and solar views to determine if the attenuators are operating properly. Instrument nonlinearity is determined using a range of attenuators while observing the Sun.

In order to achieve the RI mission objectives, the CLARREO RSS instrument will be designed to allow the boresight to be pointed along selected lines of sight within the fields of view of orbiting target sensors. The concept of these preplanned onorbit viewing geometry matching operations is described in detail in Section III for intercalibrating sensors in LEO and GEO. In this study, we assumed that the CLARREO RSS instrument is in a polar $90^{\circ}$ inclination orbit, at a $609-\mathrm{km}$ altitude. We should note that the choice of the polar $90^{\circ}$ inclination orbit is motivated by achieving optimal sampling for CLARREO climate benchmark observations [26]. The orbit altitude is chosen for two reasons - to optimize spatial coverage of the benchmark observations with a 61-day ground track repeat cycle and to fly CLARREO in a significantly lower orbit than the existing sensors to ensure reasonable slew rates for on-orbit instrument pointing.

\section{B. CLARREO RSS RI Objectives}

Due to the specifics of instrument design, we prioritize intercalibration tasks separately for broadband and narrowband sensors. The CLARREO RSS objectives for intercalibrating the CERES and VIIRS instruments are summarized in Table II, and corresponding intercalibration time scales and variables for
TABLE II

SumMary of High-PRIORITY INTERCALIBRATION TASKS. DEgREe OF Linear Polarization IS DENOTED BY $P$ AND ANGLE OF Polarization By $\chi$. UNCERTAINTY CONTRIBUTION FROM INTERCALIBRATION DATA Matching in Percent $(k=2)$ FOR CORRESPONDing TIMe Period AND REQUIRED INTERCALIBRATION SAMPLE NUMBER $N$

\begin{tabular}{|l|l|c|c|c|c|}
\hline Sensor & Parameter & Time Scale & Variable & $\begin{array}{c}\text { Uncertainty } \\
\%(k=2)\end{array}$ & $N$ \\
\hline \hline \multirow{3}{*}{ CERES } & Offset & monthly & scan angle & 0.9 & $2.5 \times 10^{3}$ \\
\cline { 2 - 6 } & Gain & monthly & scan angle & 0.9 & $2.5 \times 10^{3}$ \\
\cline { 2 - 6 } & Degradation of optics & seasonally & scene type & 0.5 & $30 \times 10^{3}$ \\
\cline { 2 - 6 } & Non-linearity & annually & all data & 0.3 & $150 \times 10^{3}$ \\
\hline \hline \multirow{5}{*}{ VIIRS } & Baseline offset & monthly & $P$, scan angle & 0.9 & $7.0 \times 10^{3}$ \\
\cline { 2 - 6 } & Baseline gain & monthly & $P$, scan angle & 0.9 & $7.0 \times 10^{3}$ \\
\cline { 2 - 6 } & Sensitivity to polarization & seasonally & $P$, scan angle, $\chi$ & 0.5 & $1.2 \times 10^{6}$ \\
\cline { 2 - 6 } & Non-linearity & annually & $P$, scan angle & 0.3 & $0.5 \times 10^{6}$
\end{tabular}

data stratification are reported. ${ }^{2}$ These objectives are based on discussions with the CERES and MODIS/VIIRS Instrument Calibration Group at NASA LaRC and Goddard Space Flight Center (GSFC) and are motivated by the following rationale.

For CERES, a scanning broadband radiometer, RI of gain, scan angle dependent electronic offset, and correction of spectral response function (SRF) are the highest priorities. The SRF is very broad (350- to 3500-nm wavelength), but optics contamination typically occurs below $500 \mathrm{~nm}$; therefore, spectral response must be verified on orbit to achieve an accurate record of Earth's radiation budget. CERES bolometer detectors are designed and verified to achieve less than $0.1 \%$ nonlinearity, and the spherical symmetry of the Cassegrainian optics is designed to eliminate polarization sensitivity. We should note that CLARREO RSS intercalibration operations on orbit are designed to match CERES climate record data, which are collected in cross-track scanning mode.

For the RI of the VIIRS instrument, a cross-track scanning narrowband imager, the highest priorities are the baseline offset and gain (not polarized) as functions of scan angle, nonlinearity, and gain corrections due to sensitivity to polarization. MODIS sensitivity to polarization is reported to be $2 \%-5 \%$, depending on band and viewing geometry [22]. Sensitivity to polarization is a response of the optic system, and it results in an additional factor to the instrument calibration function, depending on scene type and viewing geometry. The intercalibration of narrowband radiometer sensitivity to polarization by CLARREO RSS and resulting uncertainty are discussed in detail in a separate study by Lukashin et al. [12]. Change in the imager optics response function, such as central wavelength shift of narrowband, is reported to be small for both MODIS instruments on Terra and Aqua platforms [31], and therefore, its detection is not given high priority.

\section{CLARREO RSS RI Approach}

We see on-orbit RI as a multidimensional minimization of the difference between high-accuracy CLARREO RSS and intercalibrated sensor coincident measurements. The process should be performed for all available on-orbit matched data with minimal additional error contribution. Intercalibrated instrument response parameters are derived over a time period (month,

\footnotetext{
${ }^{2}$ For imagers on MetOp (AVHRR) or the GEO platforms, such as Advanced Baseline Imager on GOES-R, the intercalibration objectives are similar to those for VIIRS listed in Table II. In the case of GEO imagers, imager pointing angle takes the place of a LEO instrument cross-track scan angle.
} 
season, or year). The intercalibration approach is based on the derivation of instrument offset and gain for every intercalibration data configuration by comparison with the CLARREO RSS as a high-accuracy reference. The intercalibration configuration is data sampling defined by scan angle binning, selection of scene type, and selection of polarization range. The number of intercalibration configurations is given by CLARREO RSS intercalibration objectives as listed in Table II. It is essential that every intercalibration data configuration is provided with adequate sampling to reduce statistical data matching noise between CLARREO and intercalibrated sensor observations, and to allow offset and gain retrieval with additional uncertainty, comparable with CLARREO instrument accuracy, i.e., $0.3 \%(k=2)$ over a climate autocorrelation time period of 0.8 years (see [26, Table I]). Thus, the net intercalibration transfer uncertainty is limited to about $\sqrt{2} \times 0.3 \%(k=2)$.

A study was carried out to establish the dependence of onorbit time, space, and angle data matching noise on matching accuracy [25]. The authors used data from the AVHRR instruments on NOAA-17 and NOAA-18 satellites, when their orbits crossed. It was demonstrated that temporal and spatial mismatching results in random data noise. The spatial noise decreases as averaging space increases, and noise due to time difference decreases as the time constraint becomes smaller. The uncertainty due to viewing geometry mismatching has two components, i.e., random and systematic, that decrease as the accuracy of angular alignment improves. These results are used to set requirements for the CLARREO RSS intercalibration data matching: With CLARREO RSS spatial sampling of $0.5 \mathrm{~km}$, containing instantaneous data matching noise within $1 \%$ requires averaging over a $10-\mathrm{km}$ area for VIIRS intercalibration, or over a CERES 20-km field of view (FOV). The time difference is required to be within 5 min. Angular matching (solar zenith, viewing azimuth, and viewing zenith angles) is required to be within $\pm 1^{\circ}$; with this angular alignment, the systematic uncertainty becomes negligible. Our sampling requirements for intercalibration noise reduction are based on this noise level. In this paper, we define the intercalibration sample as data from the CLARREO RSS and the target sensor matched on orbit in time and viewing angles and averaged spatially, with the specification described above.

To derive the total number of required intercalibration samples, $N$, for a given intercalibration objective and over a specified time period (see Table II), we performed a set of additional simulations. We started with orbital modeling of CLARREO in LEO, where the CLARREO RSS boresight is pointed to match the viewing geometry of the target sensor. This step is required to obtain the geolocation distribution of the intercalibration measurements and is discussed in detail in Section III. Using the results from orbital modeling and existing CERES and Polarization and Anisotropy of Reflectances for Atmospheric Sciences coupled with Observations from a Lidar (PARASOL) data, ${ }^{3}$ we estimated the expected scene type and polarization distributions over one year of CLARREO intercalibration operations. Then, we simulated the intercalibration algorithms

\footnotetext{
${ }^{3}$ We used the CERES SSF Edition-3 data product distributed by NASA and the PARASOL Level-1 data product distributed by CNES, France.
}

using existing SCIAMACHY spectral data ${ }^{4}$ as a proxy for CLARREO RSS measurements, adding data matching noise statistically. Finally, combining inputs from all these steps, accounting for the intercalibrated sensors' data taking specifics (cross-track scanning, data rate) and CLARREO RSS spatial coverage, we estimated both the required and achievable intercalibration sampling, which we discuss in detail in Section IV-A and $\mathrm{B}$, respectively.

\section{ORbital Simulations OF INTERCALIBRATION EVENTS}

Analysis has been performed to study opportunities for CLARREO to intercalibrate instruments aboard spacecraft in LEO and GEO. Considerations common to the studies performed for both orbital regimes are discussed in the first part of this section. Analytical concepts unique to each type of orbit are then presented, together with results, in Section III-A and B, respectively.

As discussed in Roithmayr and Speth [18], analysis of intercalibration over long periods is made computationally efficient by making several simplifying assumptions with regard to orbital motions of two spacecraft about Earth, Earth's orbit about the Sun, and Earth's shape. In short, all orbits are treated as circular, and Earth is considered to have a spherical surface. Precession of a spacecraft's orbit plane with respect to an inertial reference frame is accounted for by employing a wellknown expression for orbital average nodal regression rate as a function of inclination of the orbit plane, radius of the orbit, and the parameter $J_{2}$ that quantifies Earth's oblate mass distribution. For convenience, each simulation begins at the instant of autumnal equinox, and Earth's prime meridian is placed at local midnight.

Because measurements of RS radiation are of interest, solar illumination of Earth's surface must be considered when determining whether an opportunity for intercalibration exists. For the purposes of the analysis discussed here, an opportunity is said to exist when the subsatellite points of both spacecraft lie on the illuminated hemisphere, to include the terminator.

The number of measurements suitable for intercalibration can be enlarged by directing the boresight of the RS instrument on CLARREO to a point on Earth's surface where the viewing zenith angle (VZA) to CLARREO is identical to the VZA to the other spacecraft. The boresight can be aimed by means of two successive rotations described as follows. Consider a local-vertical-local-horizontal reference frame, $L$, with $x-, y$-, and $z$-axes that are parallel to a line locally horizontal and in the plane of the orbit, a line locally horizontal and perpendicular to the orbit plane, and a line that is locally vertical, respectively. A spacecraft bus, $B$, is depicted in Fig. 1 in a nominal attitude with unit vectors $\hat{\mathbf{b}}_{1}, \hat{\mathbf{b}}_{2}$, and $\hat{\mathbf{b}}_{3}$ aligned with the aforementioned $x-, y$-, and $z$-axes. The first rotation takes place about local vertical, i.e., $\hat{\mathbf{b}}_{3}$; the angular displacement is denoted by $q_{1}$ and is referred to as yaw. Physically, the rotation

\footnotetext{
${ }^{4}$ We used the SCIAMACHY SCI_NL_1P data product distributed by the European Space Agency. We used version 7.03 of the data and the corresponding Level-1C radiometric calibration tool and version $7.01 \mathrm{of} \mathrm{m}$-factor correction for instrument optics degradation.
} 


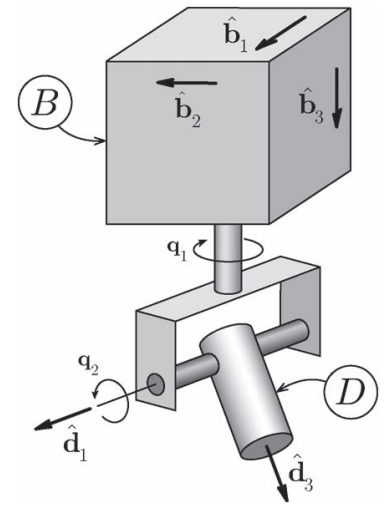

Fig. 1. Definition of the CLARREO RSS gimbal angles.

can be accomplished by yawing $B$ with respect to $L$ or by using a gimbal, as shown, to rotate the instrument, $D$, with respect to $B$. The second rotation, by an amount $q_{2}$, takes place about the instrument's $x$-axis, $\hat{\mathbf{d}}_{1}$, and is therefore called roll. Although the second rotation could be achieved by changing the attitude of $B$ in $L$, it is likely to be more practical to mount the instrument in $B$ with a gimbal, which permits a change in $q_{2}$, as illustrated in Fig. 1.

\section{A. Intercalibration With Sensors in LEO}

Analysis of CLARREO intercalibration in LEO is predicated on the assumption that the instrument aboard the other spacecraft scans in the cross-track direction, that is, perpendicular to the spacecraft's ground track. Instruments that operate in this manner include (but are not limited to) CERES on Terra, Aqua, Suomi National Polar-orbiting Partnership (Suomi NPP), and JPSS platforms and MODIS, VIIRS, and AVHRR imagers on Terra, Aqua, NPP, JPSS, and MetOp satellites. In addition, intercalibration requires that the two measurements to be compared are obtained a short time apart, as reported by Wielicki et al. [25]. The results reported here are obtained by assigning this temporal constraint a value of $5 \mathrm{~min}$.

The foregoing considerations lead one to regard an intercalibration opportunity as the period of time during which CLARREO is inside a "tent" that is attached to the other spacecraft, as illustrated in Fig. 2. The FOV of the other instrument has an angular displacement to either side of nadir; this scan angle, taken here to be $55^{\circ}$, determines the slope of the roof of the tent. Point $A$ denotes the actual position of the other spacecraft. The temporal constraint is accounted for by imagining a spacecraft $A^{+}$that is 5 min ahead of $A$ in its orbit and another spacecraft $A^{-}$that is $5 \mathrm{~min}$ behind $A$. The arc that passes through $A^{+}, A$, and $A^{-}$forms the ridge of the tent's roof. When CLARREO, which is denoted by $P$, is inside the tent, an intercalibration opportunity exists. One point $Q$ on the ridge of the tent is closest to $P$. If CLARREO's instrument is aimed toward Earth $E$, such that the boresight is parallel to the line joining $Q$ and $P$, then, at the resulting target on the surface of $E$, the VZA to $P$ is the same as it is to $Q$. The instrument aboard CLARREO has a scan angle of approximately $4.8^{\circ}$, and the boundaries of the swath are indicated with solid black curves. Within these boundaries, the RI data will be closely matched to the target sensor measurements.

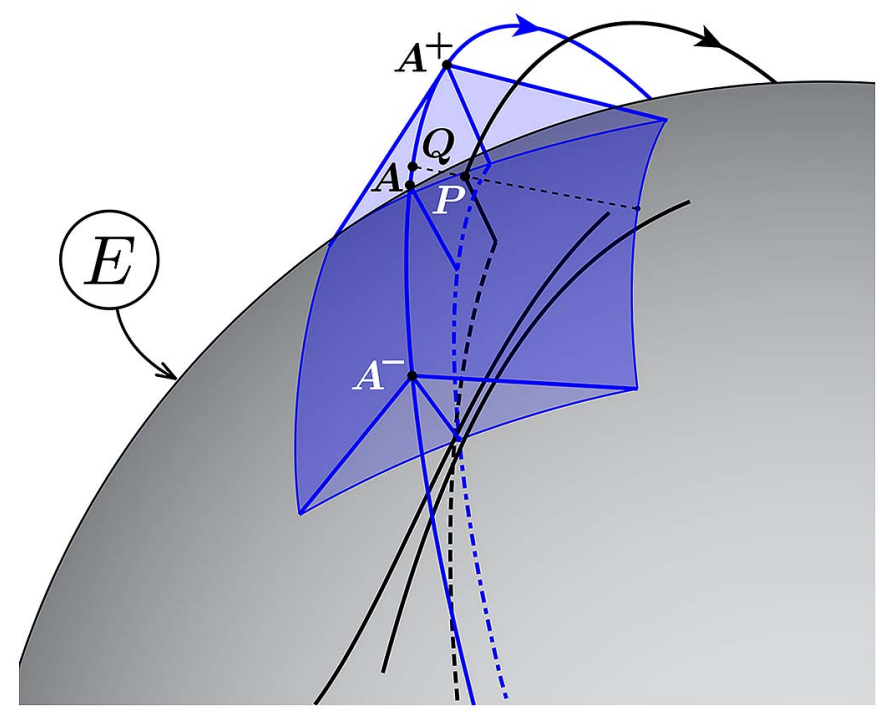

Fig. 2. Earth's surface is indicated by $E$, the blue and black lines with arrows show the orbit tracks of CLARREO (black) and the satellite carrying the cross-track scanning instrument being calibrated (blue). An intercalibration opportunity is the period of time during which CLARREO is inside a tent (shown in blue) that is attached to the other spacecraft. When CLARREO exits the tent at point $P$, intercalibration opportunity ends. Within the boundaries of the CLARREO swath, indicated by solid black curves, the RI data will be closely matched to the target sensor measurements.

TABLE III

Orbital Parameters of CLARREO, JPSS, AND MetOp Satellites

\begin{tabular}{|l|r|r|r|}
\hline Orbital Parameter & CLARREO & JPSS (13:30 local time) & MetOp (21:30 local time) \\
\hline \hline Altitude $(\mathrm{km})$ & $609($ constant $)$ & 833 (constant) & 817 (constant) \\
\hline Inclination, $i(\mathrm{deg})$ & $90($ constant $)$ & $98.74($ constant $)$ & 98.68 (constant) \\
\hline Right Ascension, $\Omega(\mathrm{deg})$ & $0($ constant $)$ & $202.5(t=0)$ & $322.5(t=0)$ \\
\hline Arg. of Latitude, $\theta(\mathrm{deg})$ & $0(t=0)$ & $0(t=0)$ & $0(t=0)$ \\
\hline
\end{tabular}

Simulations of orbital motion during a period of one year have been performed to examine intercalibration opportunities between CLARREO and two other spacecraft, i.e., JPSS and MetOp. Orbital parameters for each spacecraft are presented in Table III. CLARREO is in a polar orbit, whereas JPSS and MetOp are in near-polar Sun-synchronous orbits that pass through the ascending node at local times of 13:30 (afternoon) and 21:30 (night), respectively. The ascending node of the CLARREO orbit will pass through all $24 \mathrm{~h}$ of local time in exactly one year.

Opportunities for CLARREO to intercalibrate JPSS are depicted in Fig. 3. The ground track of CLARREO during each opportunity for the entire year is indicated in the plot in the upper left; an opportunity begins at an open circle and ends at a closed circle. The length of the ground track is proportional to the duration of the opportunity. Many opportunities of short duration occur over high latitudes, whereas a smaller number of long-duration events take place at low and middle latitudes. The plots in the upper right, lower left, and lower right in Fig. 3 correspond to 30-day periods, i.e., mission days 1-30, 31-60, and 151-180, respectively. It is shown that opportunities are predominantly over the Arctic in the first month, over the Antarctic in the second month, and over low and middle latitudes in the sixth month. This observed variation is caused by the difference in precession rate $(d \Omega / d t)$ of the ascending nodes of the two orbits and by the latitudinal change in the boundaries of the terminator during the year. 

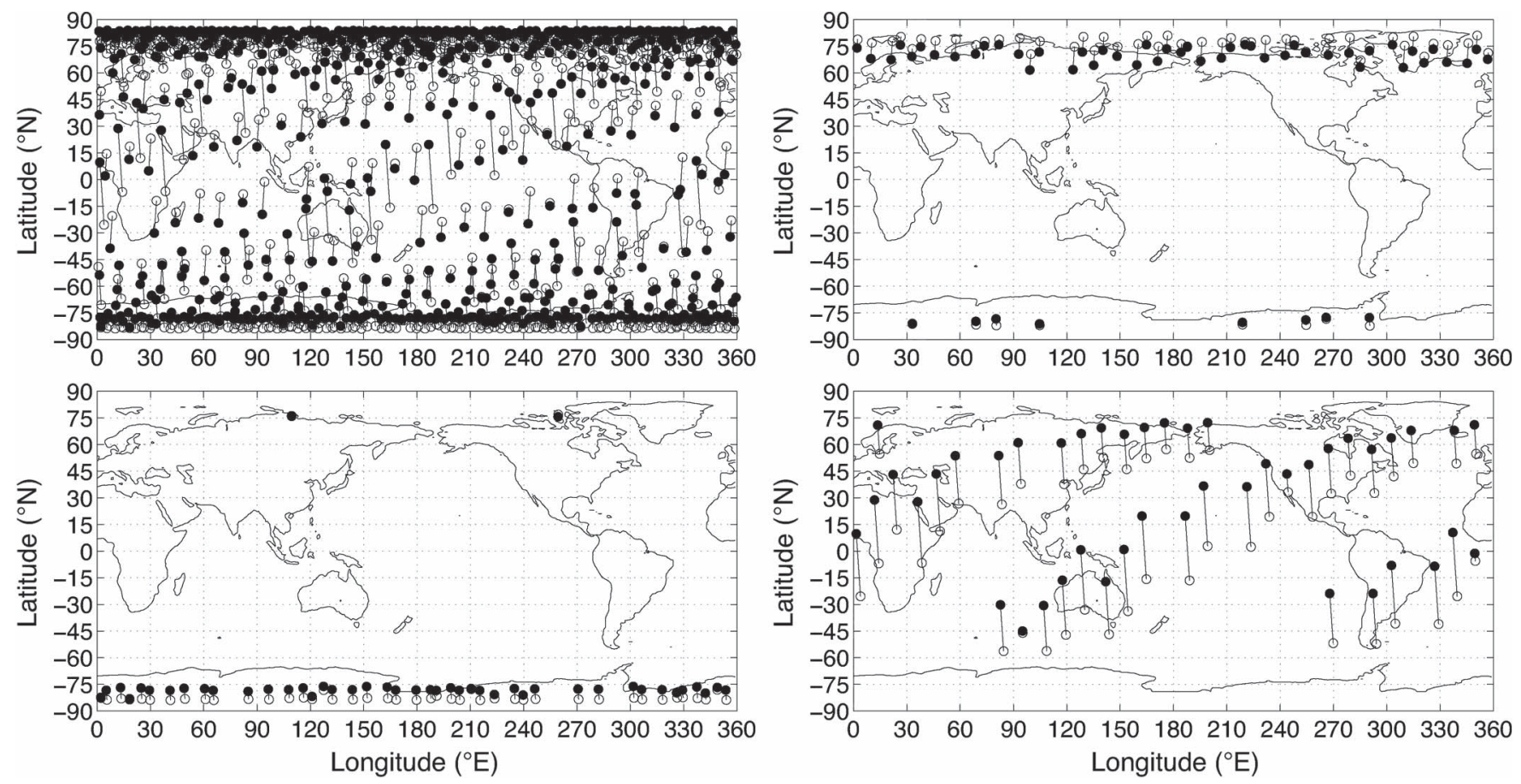

Fig. 3. Geolocation and distributions of intercalibration opportunities, CLARREO intercalibration of cross-track instruments on the JPSS satellite. (Upper left) Opportunity $(\circ)$ start and $(\bullet)$ end for an entire year. The plots in the upper right, lower left, and lower right correspond to 30-day periods, i.e., mission days 1-30, 31-60, and 151-180, respectively.
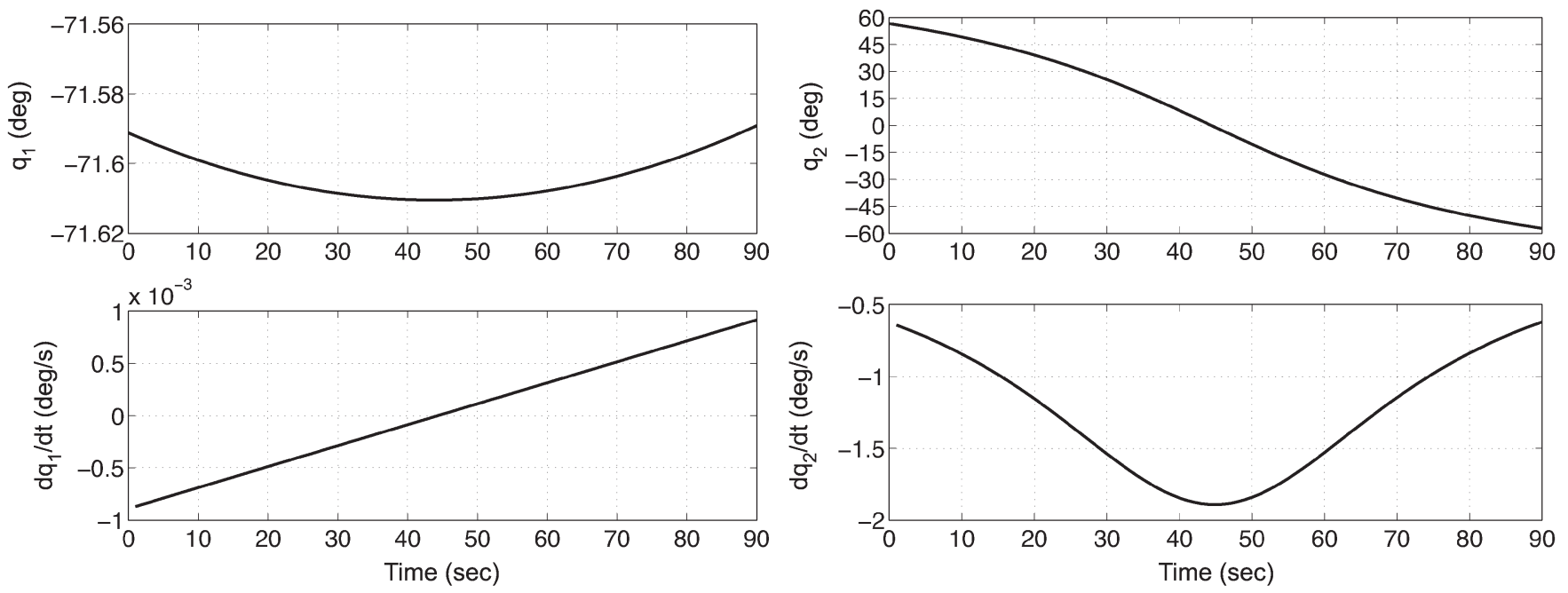

Fig. 4. CLARREO pointing motion required for on-orbit intercalibration of cross-track instruments on the JPSS satellite (LEO). Values of $q_{1}$ (yaw) and $q_{2}$ (roll) and their time derivatives are shown for one particular short-duration opportunity that takes place over high Antarctic latitudes during mission day 87.

As previously discussed, intercalibration is facilitated to a great extent when the instrument aboard CLARREO is continuously aimed during an opportunity in order to make the boresight parallel to line $Q P$ (see Fig. 2). Design of the spacecraft and/or instrument is, therefore, significantly affected by the required behavior of the angles $q_{1}$ and $q_{2}$ that determine the aim of the instrument. Plots of $q_{1}$ and $q_{2}$ and their time derivatives are shown in Fig. 4 for one particular short-duration opportunity that takes place over high Antarctic latitudes during mission day 87 . Over the 90 -s opportunity, $q_{1}$ (yaw) need only change by about $0.02^{\circ}$, and the time derivative $d q_{1} / d t$ remains less than $0.001 \%$ in absolute value. On the other hand, $q_{2}$ (roll) must change by nearly $120^{\circ}$ and $d q_{2} / d t$ must reach a magnitude of about $1.9^{\circ} / \mathrm{s}$ when the instrument boresight passes through nadir. In this case, the orbital altitudes of the two spacecraft differ by $224 \mathrm{~km}$ (see Table II); a smaller difference will result in a larger magnitude of $d q_{2} / d t$.

The duration of each opportunity over the course of a year is plotted in Fig. 5 for JPSS on the left and MetOp on the right. The opportunities having the longest durations, nearly $600 \mathrm{~s}$, occur over near-equatorial latitudes as both spacecraft are ascending or descending together through the equatorial plane; in the case of JPSS, the plot in the lower right in Fig. 3 covers the time period associated with the longest durations. In $600 \mathrm{~s}$, the boresight of CLARREO's instrument traces a path approximately $4200 \mathrm{~km}$ long on Earth's surface; at every point on this path, viewing angles to both spacecraft are identical. Two minima are evident in each plot appearing on the top 

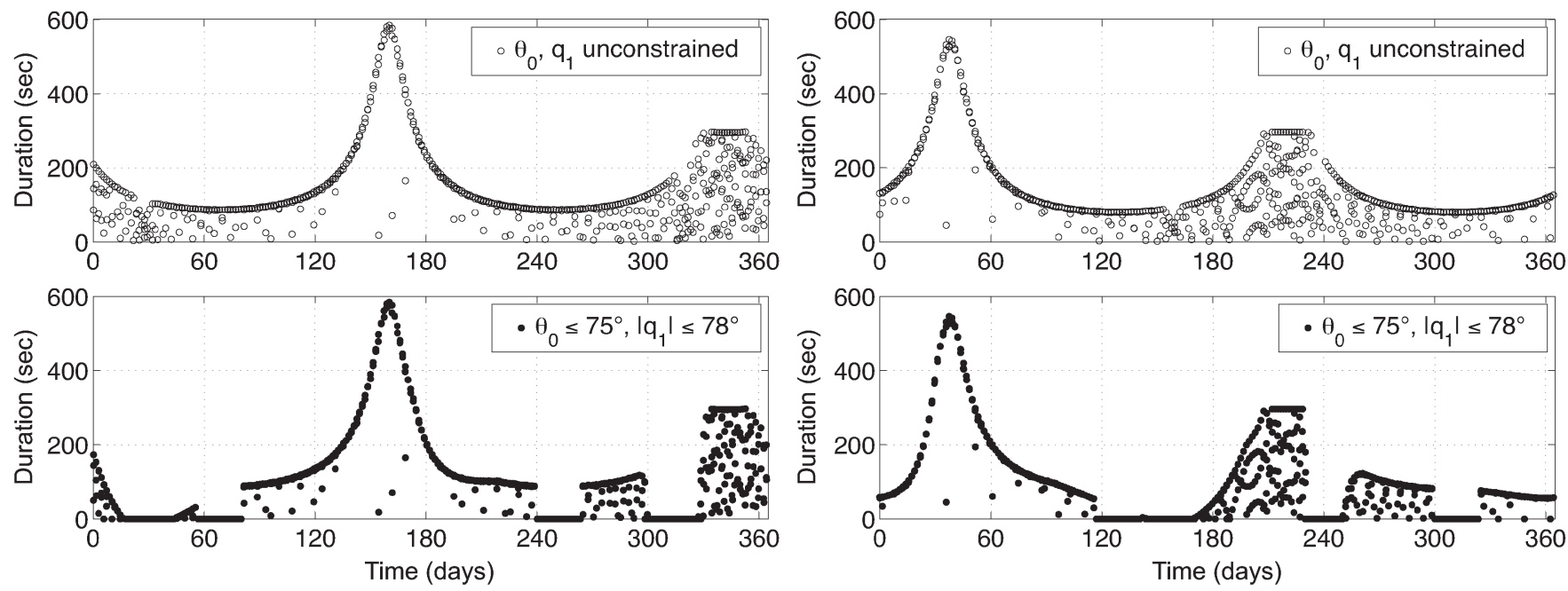

Fig. 5. Intercalibration opportunity durations for one year of simulated operations. CLARREO intercalibration of cross-track instruments on (left) JPSS, 661 opportunities and (right) MetOp, 652 opportunities. (Top) No constraints. (Bottom) SZA $\leq 75^{\circ}$ and $\left|q_{1}\right| \leq 78^{\circ}$.

in Fig. 5; they occur six months apart and correspond to opportunities taking place over high latitudes. In each plot, a secondary maximum, separated from the peak by six months, occurs at a time when one spacecraft is ascending and the other is descending through the equatorial plane.

According to Minnis et al. [15], measurements of RS radiation are useful for intercalibration when the SZA is $75^{\circ}$ or less. Moreover, the effective swath width for the instrument aboard CLARREO becomes unacceptably small when the yaw angle $q_{1}$ exceeds $78^{\circ}$. Durations are plotted on the top or the bottom, depending on whether the calculations do not or do take into account the two constraints, respectively. In the latter case, it can be seen that intervals lasting a month or more may pass during which no suitable measurements are available.

We have performed other year-long simulations of CLARREO in a $90^{\circ}$ inclination orbit, with right ascension $\Omega=$ $10^{\circ}, 20^{\circ}, 30^{\circ}, \ldots, 350^{\circ} . \Omega=0^{\circ}, 180^{\circ}$ maximizes the number of useful measurements that can be obtained, whereas $\Omega=90^{\circ}$, $270^{\circ}$ minimizes the number. As $\Omega$ increases from $0^{\circ}$ to $90^{\circ}$, the constraint that SZA be $\leq 75^{\circ}$ produces progressively longer periods of time during the year when no useful measurements can be obtained to intercalibrate JPSS or MetOp. A requirement for $\Omega=0^{\circ}$ or $180^{\circ}$ will, in turn, impose a requirement on time of launch, depending on the location and date of the launch. We have also investigated the amount of sampling that can be obtained with CLARREO in precessing orbits with inclinations of $82^{\circ}$ and $74^{\circ}$. Better sampling is obtained in tropical regions; however, sampling in polar regions is eliminated, and this prevents CLARREO from obtaining global climate benchmark sampling.

\section{B. Intercalibration With Sensors in GEO}

Instruments carried on satellites in GEO do not scan in the cross-track direction; therefore, the analytical approach discussed in Section III-A requires modification.

In Fig. 6, $G$ denotes the position of a spacecraft in GEO, $E^{\star}$ marks the center of Earth $E$, and $C$ is a sphere whose surface contains CLARREO. For convenience, $E$ and $C$ are depicted as hemispheres. An instrument at $G$ scans a region on Earth's
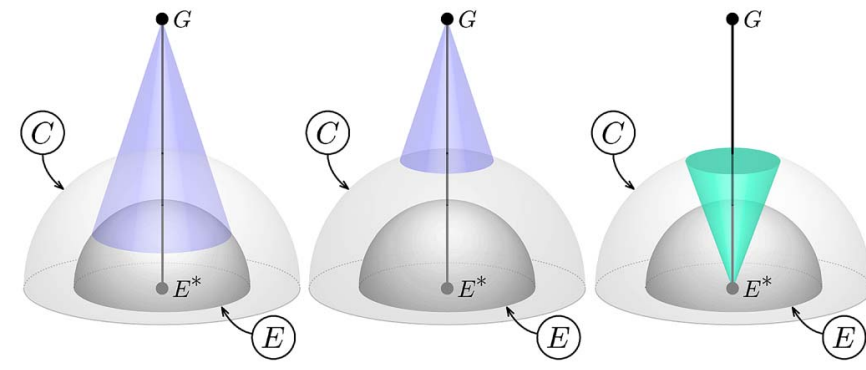

Fig. 6. Cones used for detecting opportunities for CLARREO intercalibration of GEO-based imagers.

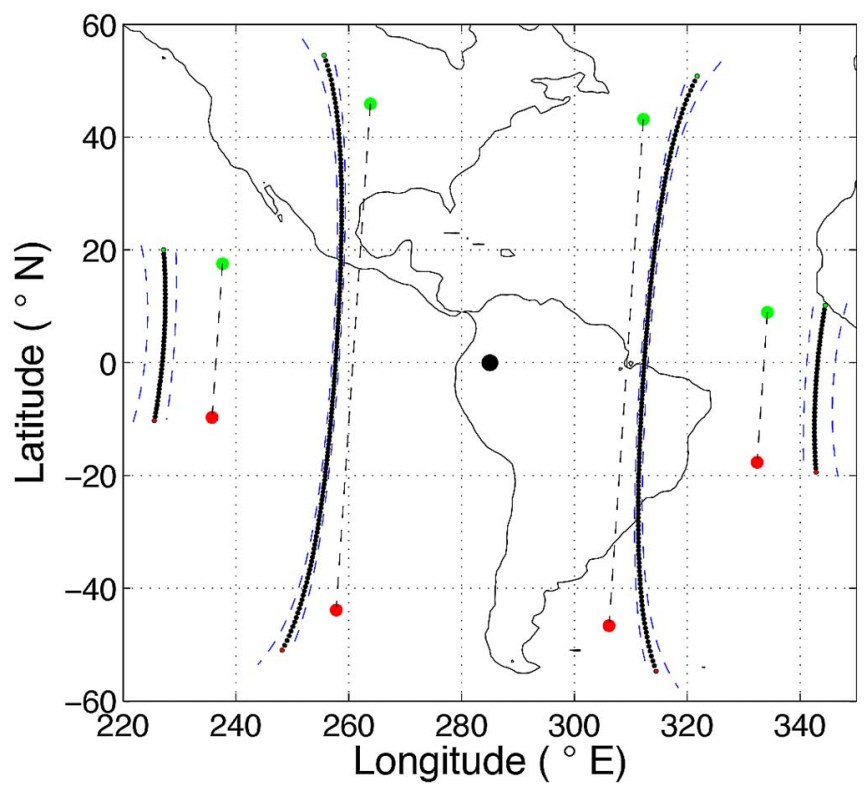

Fig. 7. CLARREO and GEO-based imager matched data for one day period: CLARREO (solid black curves) boresight ground tracks and (dashed blue lines) swath edges. Solid black circle indicates GEO subsatellite point, and black dashed lines show CLARREO ground track during intercalibration event.

surface that is centered at the subsatellite point on the equator; the region may be regarded as the intersection of the blue cone with $E$, as shown in the leftmost illustration. On the meridian 

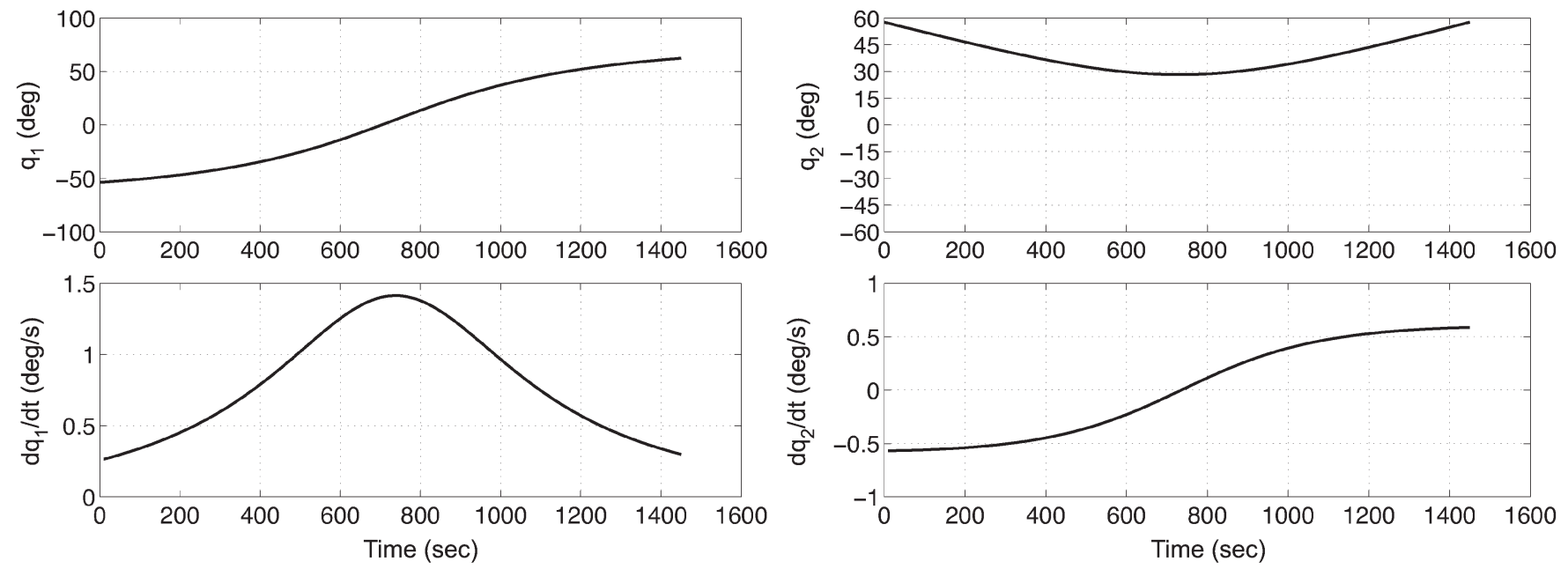

Fig. 8. CLARREO pointing motion required for on-orbit intercalibration with GEO-based imager. Values of $q_{1}$ (yaw) and $q_{2}$ (roll) and their time derivatives are shown for one intercalibration opportunity.

that contains the subsatellite point, the scanned region equally extends by an angle $\lambda$ of latitude to the north and south. On the equator, the region extends in longitude to the east and west of the subsatellite point by the same angle $\lambda$. A typical value of $\lambda$ is $60^{\circ}$. The region is scanned once every $15 \mathrm{~min}$, approximately. Future instruments, such as the GOES-R Advanced Baseline Imager, will also obtain measurements in a similar manner [20].

In the analysis previously discussed in Section III-A, existence of an opportunity to intercalibrate LEO spacecraft is determined with the aid of a pyramid whose vertex is $E^{\star}$, as explained in Roithmayr and Speth [18]. The pyramid is intimately related to the tent (see Fig. 2). For analysis of GEO intercalibration, the tent and pyramid are replaced with the blue and green cones shown in Fig. 6, respectively. Existence of an opportunity to intercalibrate GEO spacecraft is easily established; it occurs when the angle between the position vector from $E^{\star}$ to $G$ and the position vector from $E^{\star}$ to CLARREO is less than or equal to the half-angle of the green cone.

In analysis of intercalibration with LEO spacecraft, a temporal constraint on the measurements is represented by the length of the tent roof's ridge. The cone used for analysis of GEO intercalibration does not lend itself easily to application of a temporal constraint; however, as an estimate, the temporal difference in measurements will not exceed half of the period taken by the GEO instrument to complete a scan. For example, if an instrument in GEO performs a scan every $15 \mathrm{~min}$, a comparable measurement will be obtained by CLARREO within $7.5 \mathrm{~min}$.

During an intercalibration opportunity, the boresight of the instrument on CLARREO can be aimed so that it is parallel to a line joining the two spacecraft, $G$ (see Fig. 6) and CLARREO. At the resulting target on Earth's surface, the VZA to CLARREO is the same as it is to $G$.

Analysis has been performed for a GEO spacecraft stationed at a longitude of $75^{\circ} \mathrm{W}$ (GOES-East). During a typical day, CLARREO has four intercalibration opportunities, as shown in Fig. 7. Green and red markers indicate the beginning and end of an opportunity, respectively; and the dashed lines joining the markers represent the ground tracks of CLARREO. Solid black curves mark the CLARREO instrument boresight paths; dashed lines on either side of the curves indicate the extent of swath of the instrument.

During a typical intercalibration opportunity, the instrument boresight is aimed by varying angles $q_{1}$ (yaw) and $q_{2}$ (roll), as shown in Fig. 8. The behavior of $q_{1}$ markedly differs from what is shown in Fig. 4 in connection with LEO intercalibration; here, $q_{1}$ varies by over $100^{\circ}$ and $d q_{1} / d t$ grows to nearly $1.5^{\circ} \mathrm{s}$ when the distance between the two subsatellite points reaches a minimum. In fact, $d q_{1} / d t$ becomes infinite when the subsatellite points are coincident; therefore, steps are taken in the analysis to avoid opportunities that involve a small distance between subsatellite points.

\section{INTERCALIBRATION DATA SAMPLING ESTIMATES}

To derive intercalibration sampling requirements and estimate projected sampling, we combined the results from orbital modeling, CLARREO RSS on-orbit data matching, and target sensor's scanning mode with a simulated intercalibration algorithm and existing data analysis. Here, we illustrate the CLARREO RSS intercalibration approach using examples of the CERES and VIIRS instruments on the JPSS satellite.

\section{A. Intercalibration Data Sampling Requirements}

To derive a numerical sampling requirement for each intercalibration goal (see Table II), we performed additional simulation of CLARREO and CERES intercalibration using SCIAMACHY hyperspectral radiance data. We used integrated SCIAMACHY spectral radiance $I_{\text {scia }}$ as a proxy for the CLARREO RSS broadband measurement $I_{\text {clarreo, }}$

$$
I_{\text {clarreo }}=\left[\sum_{\lambda} I_{\text {scia }}(\lambda)\right]
$$

and simulated CERES broadband observations $I_{\text {ceres }}$ by integrating and applying changes in offset, gain, and spectral response of the instrument,

$$
I_{\text {ceres }}=p_{G} \times\left[A+G \sum_{\lambda} D(\lambda) I_{\text {scia }}(\lambda)\right]
$$



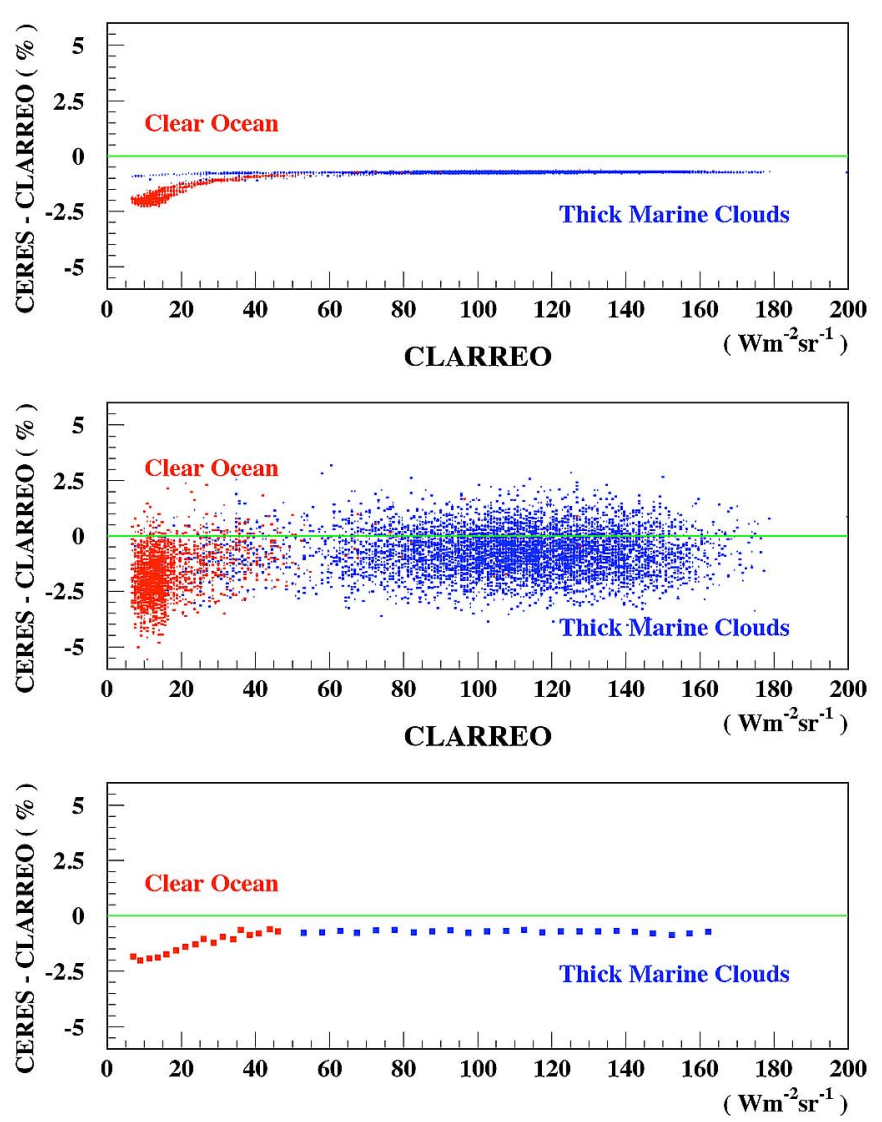

Fig. 9. Relative difference between simulated CERES and CLARREO signals plotted versus CLARREO signal. (Top) Simulation for clear-sky ocean (red) and marine clouds (blue) scenes with only RSR change in CERES. (Middle) Simulation for clear-sky ocean (red) and marine clouds (blue) scenes, which includes RSR change in CERES and simulated random matching noise of $1 \%$. (Bottom) Clear-sky ocean (red) and marine clouds (blue) simulated data after reduction of matching noise by averaging in radiance bins with a requirement of at least 100 data points.

where $A$ is offset, $G$ is gain, $D(\lambda)$ is spectral degradation, and $p_{G}$ is the Gaussian random noise factor. One case of simulation results is shown in Fig. 9: we applied degradation of CERES relative spectral response (RSR) $D=1-e^{-9.8155 \lambda}$ ( $D=0.999$ at $\lambda=0.7 \mu \mathrm{m}$ ). This shape of spectral degradation is used in the current CERES calibration approach (see [11, App. 1]). The relative difference between simulated CERES and CLARREO signals is plotted versus CLARREO signal on all three panels in Fig. 9: (top) simulation for clear-sky ocean (red, 1800 samples) and marine clouds (blue, 7000 samples) scenes with only CERES RSR change applied, (middle) simulation for clear ocean (red) and marine clouds (blue) scenes, which includes CERES RSR change and random matching noise of $1 \%$, and (bottom) clear ocean (red) and marine clouds (blue) simulated data after reduction of matching noise by averaging in radiance bins with a requirement of at least 100 data points per bin. These specific scene types were used because of very different reflected radiance spectra: the spectrum from clear-sky ocean peaks in the blue, and the spectrum from thick marine clouds has a strong signal over the range of all visible wavelengths. As expected, the simulations are consistent with early analyses of the CERES
TABLE IV

Estimated Percentile of Clear-Sky SCenes in ANNUAL AND GLOBAL INTERCALIBRATION SAMPLING, BASED ON ORBITAL MODELING OF THE INTERCALIBRATION OPPORTUNITIES AND THE CERES SSF DATA

\begin{tabular}{|l|c|c|}
\hline Surface Type & Tropic Clear (\%) & Non-Tropic Clear (\%) \\
\hline \hline Ocean & 2.923 & 1.400 \\
\hline Evergreen Forest & 0.040 & 0.114 \\
\hline Bright Desert & 0.815 & 0.071 \\
\hline Snow & 0.010 & 6.339 \\
\hline
\end{tabular}

\section{TABLE V}

Estimated Relative Fraction of Data in the AnNual and Global INTERCALIBRATION SAMPLING BOUNDED BY DOP TOP LIMIT, BASED ON ORBITAL MODELING OF THE INTERCALIBRATION OPPORTUNITIES AND THE PARASOL DATA

\begin{tabular}{|l|c|c|c|c|c|c|c|}
\hline DOP Range (DOP $<\mathrm{X})$ & $<0.05$ & $<0.1$ & $<0.2$ & $<0.3$ & $<0.4$ & $<0.5$ & $<75$ \\
\hline \hline Data Fraction (\%), $\lambda=490 \mathrm{~nm}$ & 24.2 & 55.0 & 79.8 & 89.5 & 94.6 & 97.6 & 99.98 \\
\hline Data Fraction (\%), $\lambda=670 \mathrm{~nm}$ & 46.4 & 71.8 & 87.3 & 93.9 & 97.2 & 98.9 & 99.77 \\
\hline Data Fraction (\%), $\lambda=865 \mathrm{~nm}$ & 65.5 & 81.6 & 91.5 & 96.1 & 98.4 & 99.5 & 99.98 \\
\hline
\end{tabular}

shortwave data (see [11, App. 1]) — the decrease in signal is more pronounced for clear-sky ocean scenes than for cloudy scenes. Detection of dependence of CERES instrument response on selected scene type and, therefore, spectral change in RSR is the basis for the CLARREO RSS intercalibration approach.

We performed a linear regression fit of the noise-reduced difference between CERES and CLARREO and determined the dominant uncertainty-the uncertainty of the offset term for the clear-sky ocean scenes, i.e., $0.21 \% \quad(k=2) \quad(1800$ samples). Using this, scaling the uncertainty and assuming intercalibration of CERES offset and gain every month, in ten scan angle bins, we derived the required sampling number as $N=2.5 \times 10^{3}$ (see Table II). To derive the sampling requirement for CERES seasonal intercalibration of its RSR, we used results from the orbital modeling and simulated the scene type distribution based on the CERES SSF data product. The estimated percentile of clear-sky scenes in annual intercalibration sampling is shown in Table IV. Since the clear-sky ocean scenes are required to perform the RSR intercalibration, we used a factor of 30 (about $3 \%$ of clear-sky ocean in tropics) to obtain the requirement: $N=30 \times 10^{3}$ of intercalibration samples (see Table II).

To derive intercalibration sampling requirements for VIIRS, we used orbital modeling and PARASOL data to determine the frequency distribution of polarization within global intercalibration sampling. The estimated relative fraction of data in the annual intercalibration sampling, bounded by degree of polarization (DOP) top limit, is shown in Table $\mathrm{V}$ for wavelengths 490, 670, and $865 \mathrm{~nm}$. Using this result, we derived the VIIRS monthly intercalibration requirements: a factor of 2 for DOP $\leq$ $0.05(670 \mathrm{~nm})$, a factor of 7 for scan angle bins, and a factor of 2 for each of the half-angle mirror (HAM) sides: $N=7 \times 10^{3}$ (see Table II). To derive the requirement for the VIIRS seasonal intercalibration of its sensitivity to polarization, we used a factor of 10 for DOP $=0.2-0.4$ (at $670 \mathrm{~nm}$ ), a factor of 7 for scan angle bins, a factor of 9 for bins in polarization angle, and a factor of 2 for each of the HAM sides: $N=1.2 \times 10^{6}$ (see Table II). 

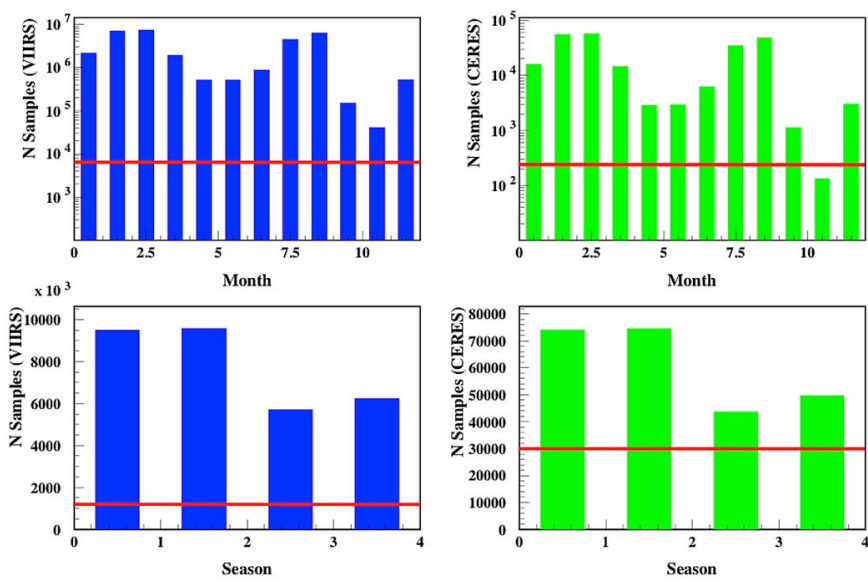

Fig. 10. Estimated (top) monthly and (bottom) seasonal sampling of CLARREO RSS in the polar $90^{\circ}$ inclination orbit intercalibrating the VIIRS (blue) and CERES (green) instruments on the JPSS. The red lines show the required sampling to meet CLARREO RSS intercalibration objectives.

\section{B. Intercalibration Achievable Data Sampling}

Combining results from our orbital modeling, assuming that the CLARREO RSS swath is $100 \mathrm{~km}$ (nadir equivalent), and predicting the CERES and VIIRS cross-track operations, we estimated the achievable intercalibration sampling monthly and seasonally over one year of CLARREO mission time. The overall restrictions for both CERES and VIIRS intercalibration are as follows: 1) SZA $<75^{\circ}$ (to ensure high signal-to-noise ratio); 2) CLARREO effective swath $>10 \mathrm{~km}$ for VIIRS and $>25 \mathrm{~km}$ for CERES; 3) VZA matching within $1.4^{\circ}$ for the entire CLARREO RSS swath, SZA and relative azimuth (RAZ) are matched within $1^{\circ}$; 4) intercalibration opportunity duration was required to be at least $10 \mathrm{~s}$. The sampling estimates, which are shown in Fig. 10, are monthly (top) and seasonal (bottom) for CLARREO RSS in the polar $90^{\circ}$ inclination orbit intercalibrating the VIIRS (blue) and CERES (green) instruments on the JPSS. The red lines show the required sampling to meet CLARREO RSS intercalibration objectives.

In estimating intercalibration sampling with CERES, we took into account the size of CERES point spread function (PSF) at $2.6^{\circ}$ in the along-track direction and a data acquisition rate of 330 measurements in each $180^{\circ}$ cross-track scan performed over $3.3 \mathrm{~s}$ [27].

In estimating intercalibration sampling with VIIRS, we considered the area included within $1^{\circ}$ of elevation angle $\left(10 \times 10 \mathrm{~km}^{2}\right.$ at nadir $)$ as a single intercalibration sample. To estimate the total number of intercalibration samples with independent spatial matching noise, we counted all possible samples in the matched data, shifting them in both directions (along and perpendicular to the ground track) for $0.1^{\circ}$ (1 km at nadir). With the CLARREO RSS spatial sampling of $0.5 \times 0.5 \mathrm{~km}^{2}$ (nadir), such a shift ensures that only two boundary pixels are common for consecutive samples. ${ }^{5}$

${ }^{5}$ It should be noted that the described approach of forming a CLARREO/VIIRS intercalibration sample does not allow intercalibration on a detector-by-detector basis. Relative calibration of VIIRS detectors to each other is required using VIIRS data alone and would be performed using common histogram equalization methods [24] or an overlapping FOV method [4].
As shown in Fig. 10, the estimated achievable intercalibration sampling for the CLARREO RSS in a polar $90^{\circ}$ inclination orbit meets the mission objectives and is sufficient to intercalibrate CERES and VIIRS instruments monthly and seasonally, with uncertainty required for measuring long-term climate change. Over a climate autocorrelation time period of 0.8 years, the statistical uncertainty contribution from data matching can be contained within $0.3 \%(k=2)$. In the case of CERES monthly intercalibration, the predicted sampling is below the required number for only one month out of the year.

\section{Discussion}

We have described the CLARREO mission approach for performing intercalibration on orbit in the RS wavelength range. It is based on providing coincident highly accurate spectral reflectance and reflected radiance measurements from the CLARREO RSS to establish an on-orbit reference for existing sensors: CERES and VIIRS on the JPSS satellite, AVHRR and follow-on imagers on MetOp, and imagers on geostationary platforms. The data matching is achieved through CLARREO pointing operations on orbit, after accounting for each target sensor's viewing geometry. We have performed a comprehensive set of modeling, data analysis, and algorithm simulations to determine mission requirements and have estimated intercalibration sampling. The results of this study show that the CLARREO RSS in a 609-km-altitude orbit with $90^{\circ}$ inclination would provide adequate sampling for intercalibration tasks of the CERES and VIIRS instruments on the JPSS platform.

We can outline the CERES intercalibration procedure by referencing CLARREO RSS observations as follows.

1) Merge data by spatially convolving CLARREO pixels over the CERES PSF and integrating spectral data into broadband.

2) Stratify all available cloudy footprints in VZA and derive scan-dependent offset and gain corrections. It is expected that CERES gain should be the same for all VZA values.

3) Generate a series of candidates for degradation of the CERES SRF in orbit. Select clear-sky ocean and medium to thick cloud scenes from matched data. Perform data noise reduction by averaging.

4) Use CERES offset and gain from 2. Select the best SRF candidate for which offset and gain difference are zero for both scene types. The requirement is driven by clear-sky ocean sampling.

We suggest the following steps for CLARREO RSS and VIIRS intercalibration:

1) Convolve CLARREO RSS and VIIRS data over areas of $10 \times 10 \mathrm{~km}^{2}$ and CLARREO RSS spectral data over VIIRS RSR into narrowband reflectances.

2) Select matched data with low DOP by applying polarization distribution models (PDMs) [12] and derive baseline gain and offset corrections in seven scan angle bins.

3) Using PDMs, stratify matched data in DOP (bin width 0.1 ) and scan angle and derive the imager's sensitivity to polarization as described in a separate publication by Lukashin et al. [12]. 
The methodology of CLARREO RSS intercalibration with narrowband imagers in GEO is essentially the same as for the VIIRS instrument. Orbital modeling for intercalibration with sensors in geostationary orbit, described in Section III-B, shows that there will be three to five CLARREO orbits per day in which its sensor coverage overlaps that of a GEO sensor. Therefore, the intercalibration sampling of the CLARREO RSS and imagers in GEO will be abundant.

We should note that, in the case of CLARREO RSS intercalibration with VIIRS, we consider our estimates to be conservative, e.g., a more sophisticated approach for spatial data convolution can increase the intercalibration sampling. In addition, the data matching noise decreases with decreasing time difference between CLARREO RSS and target sensor observations, which is the case for many intercalibration events. The focus of our future research will be on developing more sophisticated sampling algorithms for intercalibration of imagers in LEO and GEO, with implementation and validation using existing observations from the MODIS and VIIRS instruments. The advantage of a more efficient sampling algorithm is in the flexibility to reduce the required duration of pointing operations on orbit.

The intercalibration sampling of CLARREO RSS, flying a single instrument in a polar $90^{\circ}$ orbit at a $609 \mathrm{~km}$ altitude, with cross-track sensors on the JPPS platform, is scarce for one month out of a one-year period. This is due to solar geometry. A few mitigation strategies can be considered to improve uniformity of intercalibration sampling.

1) Two CLARREO RSS instruments in different polar $90^{\circ}$ orbits. This was the baseline configuration at the time of the CLARREO Mission Concept Review in November 2010.

2) Fly a CLARREO RSS instrument in a precessing orbit, for example, on the International Space Station (ISS). The CLARREO/ISS mission option could achieve $70 \%$ of the baseline mission science at a cost of $40 \%$ of the baseline mission [26]. The intercalibration sampling over a oneyear time period from the ISS is described in [19].

3) Relax the temporal data matching constraint for a given time period. This will increase the number of intercalibration opportunities, but it will also increase data matching noise.

\section{CONCLUSION}

The CLARREO mission objectives for intercalibration are to provide an on-orbit high-accuracy standard, i.e., $0.3 \%(k=2)$ of broadband reflectance, and sufficient intercalibration sampling for relevant existing sensors. The CLARREO mission approach represents the next step in achieving high accuracy in Earth's observations. A unique feature of the CLARREO RSS approach is an on-orbit 2-D pointing ability; this allows planning and executing intercalibration operations and maximizing (optimizing) the amount of matched intercalibration data for a given target sensor. In this paper, we have addressed CLARREO intercalibration sampling with CERES and VIIRS on JPSS satellites, AVHRR and follow-on imagers on MetOp, and imagers on geostationary platforms. We conclude that estimated intercalibration sampling will limit the uncertainty contribution from data matching noise to $0.3 \%(k=2)$ over the climate autocorrelation time period. The orbital modeling and intercalibration event prediction developed here will serve as a framework for future mission operations.

\section{APPENDIX \\ LIST OF ACRONYMS}

AVHRR

CERES

CLARREO

Advanced Very High Resolution Radiometer Clouds and Earth's Radiant Energy System

\section{Observatory}

DCC Deep convective clouds

FOV Field of view

GEO Geostationary Earth orbit

GERB Geostationary Earth Radiation Budget

GFOV Ground field of view

GOES-R Geostationary Operational Environmental Satellite R-Series

GSFC Goddard Space Flight Center

HAM Half-angle mirror

JPSS Joint Polar Satellite System

LaRC Langley Research Center

LEO Low Earth orbit

MODIS Moderate Resolution Imaging Spectroradiometer

RAZ Relative (solar) azimuth

RS Reflected solar

RSR Relative spectral response

SCIAMACHY SCanning Imaging Absorption spectroMeter for Atmospheric CartograpHY

SNO Simultaneous nadir overpass

SZA Solar zenith angle

TRUTHS Traceable Radiometry Underpinning

Terrestrial- and Helio- Studies

VIIRS Visible Infrared Imaging Radiometer Suite

VZA Viewing zenith angle

\section{ACKNOWLEDGMENT}

The authors would like to thank the European Space Agency for providing SCIAMACHY Level-1B spectral data, the SCIAMACHY team for helping in understanding the instrument calibration, and the PARASOL data distribution centers at CNES, France, for providing data. They would also like to thank N. G. Loeb, D. R. Doelling, K. Priestly, and X. Xiong for helpful discussions on the subject of intercalibration.

\section{REFERENCES}

[1] Earth Science and Applications From Space: National Imperatives for the Next Decade and Beyond. Washington, DC, USA: National Academies Press, 2007, Space Studies Board, National Research Council.

[2] Evaluation of Measurement Data-Guide to the Expression of Uncertainty in Measurement, Bureau International des Poids et Mesures (BIPM), Joint Committe for Guides in Metrology (JCGM), Sèvres, France, 2008.

[3] N. Clerbaux, J. E. Russell, S. Dewitte, C. Bertrand, D. Caprion, B. De Paepe, L. Gonzalez Sotelino, A. Ipe, R. Bantges, and H. E. Brindley, "Comparison of GERB instantaneous radiance and flux products with CERES edition-2 data," Remote Sens. Environ., vol. 113, no. 1, pp. 102114, Jan. 2009. 
[4] M. di Bisceglie, R. Episcopo, C. Galdi, and S. L. Ullo, "Destriping MODIS data using overlapping field-of-view method," IEEE Trans. Geosci. Remote Sens., vol. 47, no. 2, pp. 637-651, Feb. 2009.

[5] D. R. Doelling, D. Morstad, B. R. Scarino, R. Bhatt, and A. Gopalan, "The characterization of deep convective clouds as an invariant calibration target and as a visible calibration technique," IEEE Trans. Geosci. Remote Sens., vol. 51, no. 3, pp. 1147-1159, Mar. 2013.

[6] D. R. Doelling, B. R. Scarino, D. Morstad, A. Gopalan, R. Bhatt, C. Lukashin, and P. Minis, "The intercalibration of geostationary visible imagers using operational hyperspectral SCIAMACHY radiances," IEEE Trans. Geosci. Remote Sens., vol. 51, no. 3, pp. 1245-1254, Mar. 2013.

[7] N. Fox, A. Kaiser-Weiss, W. Schmutz, K. Thome, D. Young, B. Wielicki, R. Winkler, and E. Woolliams, "Accurate radiometry from space: An essential tool for climate studies," Philos. Trans. R. Soc. London A, Math. Phys. Sci., vol. 369, no. 1953, pp. 4028-4063, Oct. 2011.

[8] M. Goldberg, G. Ohring, J. Butler, C. Cao, R. Datla, D. Doelling, V. Gärtner, T. Hewison, B. Iacovazzi, D. Kim, T. Kurino, J. Lafeuille, P. Minnis, D. Renaut, J. Schmetz, D. Tobin, L. Wang, F. Weng, X. Wu, F. Yu, P. Zhang, and T. Zhu, "The Global Space-Based Inter-Calibration System (GSICS)," Bull. Amer. Meterorol. Soc., vol. 92, no. 4, pp. 467-475, Apr. 2011.

[9] N. G. Loeb, N. M. Smith, S. Kato, W. F. Miller, S. K. Gupta, P. Minnis, and B. A. Wielicki, "Angular distribution models for top-of-atmosphere radiative flux estimation from the Clouds and the Earth's Radiant Energy System instrument on the Tropical Rainfall Measuring Mission Satellite. Part I: Methodology," J. Appl. Meteorol., vol. 42, no. 2, pp. 240-265, Feb. 2003.

[10] N. G. Loeb, S. Kato, K. Loukachine, and N. M. Smith, "Angular distribution models for top-of-atmosphere radiative flux estimation from the Clouds and the Earth's Radiant Energy System instrument on the Terra satellite. Part I: Methodology," J. Atmos. Ocean. Technol., vol. 22, no. 4, pp. 338-351, Apr. 2005.

[11] N. G. Loeb, S. Kato, W. Su, T. Wong, F. G. Rose, D. R. Doelling, J. R. Norris, and X. Huang, "Advances in understanding top-ofatmosphere radiation variability from satellite observations," Surveys Geophys., vol. 33, no. 3/4, pp. 359-385, Jul. 2012.

[12] C. Lukashin, B. A. Wielicki, D. F. Young, K. Thome, Z. Jin, and W. Sun, "Uncertainty estimates for imager reference inter-calibration with CLARREO Reflected Solar Spectrometer," IEEE Trans. Geosci. Remote Sens., vol. 51, no. 3, pp. 1425-1436, Mar. 2013.

[13] F. Maignan, F.-M. Bréon, E. Fedele, and M. Bouvier, "Polarized reflectances of natural surfaces: Spaceborne measurements and analytical modeling," Remote Sens. Environ., vol. 113, no. 12, pp. 2642-2650, Dec. 2009

[14] G. Meister, E. J. Kwiatkowska, B. A. Franz, F. S. Patt, C. Feldman, and C. R. McClain, "Moderate-Resolution Imaging Spectroradiometer ocean color polarization correction," Appl. Opt., vol. 44, no. 26, pp. 5524-5535, Sep. 2005.

[15] P. Minnis, D. R. Doelling, L. Nguyen, W. F. Miller, and V. Chakrapani, "Assessment of the visible channel calibrations of the VIRS on TRMM and MODIS on Aqua and Terra," J. Atmos. Ocean. Technol., vol. 25, no. 3, pp. 385-400, Mar. 2008.

[16] F. Nadal and F.-M. Bréon, "Parameterization of surface polarized reflectance derived from POLDER spaceborne measurements," IEEE Trans. Geosci. Remote Sens., vol. 37, no. 3, pp. 1709-1718, May 1999.

[17] G. Ohring, B. Wielicki, R. Spencer, B. Emery, and R. Datla, "Satellite instrument calibration for measuring global climate change," Bull. Amer. Meteorol. Soc., vol. 86, no. 9, pp. 1303-1313, Sep. 2005.

[18] C. M. Roithmayr and P. W. Speth, "Analysis of opportunities for intercalibration between two spacecraft," in Advances in Engineering Research, V. M. Petrova, Ed. Commack, NY, USA: Nova, 2012, ch. 13, pp. 409-436.

[19] C. M. Roithmayr, C. Lukashin, P. W. Speth, D. F. Young, B. A. Wielicki, K. J. Thome, and G. Kopp, "Opportunities to intercalibrate radiometric sensors from International Space Station," J. Atmos. Ocean. Technol., Jan. 2014, accepted for publication.

[20] T. J. Schmit, M. M. Gunshor, W. P. Menzel, J. J. Gurka, J. Li, and A. S. Bachmeier, "Introducing the next-generation advanced baseline imager on GOES-R," Bull. Amer. Meteorol. Soc., vol. 86, no. 8, pp. 10801096, Aug. 2005.

[21] G. L. Smith, Z. P. Szewczyk, P. E. Mlynczak, R. B. Lee, III, B. A. Wielicki, K. J. Priestley, J. Harries, S. Dewitte, and N. Clerbaux, "Method for comparison of GERB and CERES radiances," in Proc. SPIE, 2003, vol. 5234, pp. 423-432.

[22] J. Q. Sun and X. Xiong, "MODIS polarization-sensitivity analysis," IEEE Trans. Geosci. Remote Sens., vol. 45, no. 9, pp. 2875-2885, Sep. 2007.
[23] J. Q. Sun, X. Xiong, W. Barnes, and B. Guenther, "MODIS reflective solar bands on-orbit lunar calibration," IEEE Trans. Geosci. Remote Sens., vol. 45, no. 7, pp. 2383-2393, Jul. 2007.

[24] M. Wegener, "Destriping multiple sensor imagery by improved histogram matching," Int. J. Remote Sens., vol. 11, no. 5, pp. 859-875, May 1990.

[25] B. A. Wielicki, D. R. Doelling, D. F. Young, N. G. Loeb, D. P. Garber, and D. G. MacDonnell, "Climate quality broadband and narrowband solar reflected radiance calibration between sensors in orbit," in Proc. IEEE IGARSS, 2008, pp. I-257-I-260.

[26] B. A. Wielicki, D. F. Young, M. G. Mlynczak, K. J. Thome, S. Leroy, J. Corliss, J. G. Anderson, C. O. Ao, R. Bantges, F. Best, K. Bowman, H. Brindley, J. Butler, W. Collins, J. A. Dykema, D. R. Doelling, D. R. Feldman, N. Fox, X. Huang, R. Holz, Y. Huang, Z. Jin, D. Jennings, D. G. Johnson, K. Jucks, S. Kato, D. B. Kirk-Davidoff, R. Knuteson, G. Kopp, D. P. Kratz, X. Liu, C. Lukashin, A. J. Mannucci, N. Phojanamongkolkij, P. Pilewskie, V. Ramaswamy, H. Revercomb, J. Rice, Y. Roberts, C. M. Roithmayr, F. Rose, S. Sandford, E. L. Shirley, W. L. Smith, Sr., B. Soden, P. W. Speth, W. Sun, P. C. Taylor, D. Tobin, and $\mathrm{X}$. Xiong, "Achieving climate change absolute accuracy in orbit," Bull. Amer. Meteorol. Soc., vol. 94, no. 10, pp. 1519-1539, Oct. 2013.

[27] B. A. Wielicki, B. R. Barkstrom, E. F. Harrison, R. B. Lee, III, G. L. Smith, and J. E. Cooper, "Clouds and the Earth's Radiant Energy System (CERES): An Earth Observing System experiment," Bull. Amer. Meteorol. Soc., vol. 77, no. 5, pp. 853-868, May 1996.

[28] A. Wu, X. Xiong, D. R. Doelling, D. Morstad, A. Angal, and R. Bhatt, "Characterization of Terra and Aqua MODIS VIS, NIR, and SWIR spectral bands' calibration stability," IEEE Trans. Geosci. Remote Sens., vol. 51, no. 7, pp. 4330-4338, Jul. 2013.

[29] X. Xiong, J. Sun, X. Xie, W. Barnes, and V. Salomonson, "On-orbit calibration and performance of Aqua MODIS reflective solar bands," IEEE Trans. Geosci. Remote Sens., vol. 48, no. 1, pp. 535-546, Jan. 2010.

[30] X. Xiong, J. Q. Sun, W. Barnes, V. Salomonson, J. Esposito, H. Erives, and B. Guenther, "Multiyear on-orbit calibration and performance of Terra MODIS reflective solar bands," IEEE Trans. Geosci. Remote Sens., vol. 45, no. 4, pp. 879-889, Apr. 2007.

[31] X. Xiong, N. Che, and W. L. Barnes, "Terra MODIS on-orbit spectral characterization and performance," IEEE Trans. Geosci. Remote Sens., vol. 44, no. 8, pp. 2198-2206, Aug. 2006.

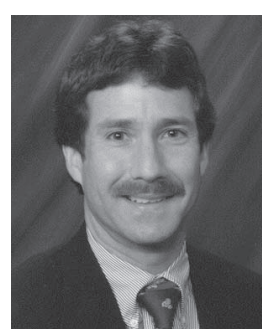

Carlos M. Roithmayr received the M.S. degree in aeronautical and astronautical engineering from Stanford University, Stanford, CA, USA, and the B.S. and Ph.D. degrees in aerospace engineering from the Georgia Institute of Technology, Atlanta, GA, USA.

He began his NASA career with the Johnson Space Center, Houston, TX, USA. He is currently a Senior Aerospace Engineer with the Langley Research Center, Hampton, VA, USA. In recent years, he has been a member of the CLARREO Mission Systems and Flight Systems teams and has developed simulations to study opportunities for intercalibration of sensors on climate science spacecraft. His research interests include dynamics of multibody mechanical systems, spacecraft attitude dynamics and control, and orbital mechanics.

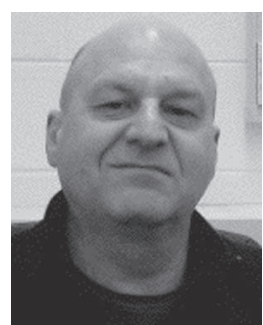

Constantine Lukashin received the M.S. degree in nuclear physics and engineering from St. Petersburg State Polytechnical University, St. Petersburg, Russia, in 1990, and the Ph.D. degree in physics from Virginia Polytechnic Institute and State University, Blacksburg, VA, USA, in 2000

From 1990 to 2001, he participated in nuclear and high-energy particle physics experiments, working at national accelerator facilities in Russia, Italy, France, and the U.S. In 2001, he joined the NASA CERES Team as a Research Scientist for development and validation of the angular distribution models (ADMs). As a member of the CERES Team, he developed an artificial neural network approach for reproducing ADMs in the absence of coincident imager observations. He is currently a Research Physical Scientist with NASA Langley Research Center, Hampton, VA, USA, where he is responsible for developing a CLARREO reference intercalibration methodology in the reflected solar wavelength range. 


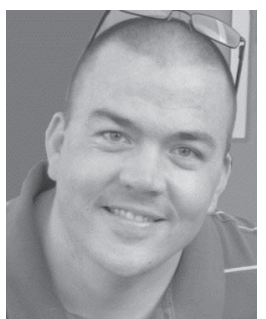

Paul W. Speth received the B.S. degree in engineering physics from Embry-Riddle Aeronautical University, Daytona Beach, FL, USA, in 2002, and the M.S. degree in aerospace engineering from Virginia Polytechnic Institute and State University, Blacksburg, VA, USA, in 2008. He is currently working toward the Ph.D. degree in systems engineering at The George Washington University, Washington, DC, USA.

He has worked with NASA Langley Research Center, Hampton, VA, for ten years, supporting the Systems Analysis and Concepts Directorate. The primary focus of his work has been in mission and spacecraft architecture formulation for human exploration, planetary, and earth science missions. He is currently the mission design Lead Engineer of the Climate Absolute Radiance and Refractivity Observatory mission, performing orbit analyses in support of sampling error and intercalibration studies.

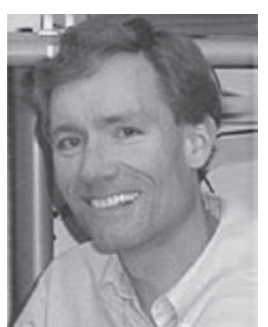

Greg Kopp received the B.S. degree in physics from California Institute of Technology, Pasadena, CA, USA, and the Ph.D. degree in physics from Stanford University, Stanford, CA.

He is currently a Research Scientist with the Laboratory for Atmospheric and Space Physics (LASP), University of Colorado, Boulder, CO, USA. He is the LASP Principal Investigator (PI) of the NASA Glory Total Irradiance Monitor (TIM), a space flight instrument designed to measure total solar irradiance to a radiometric accuracy of $0.01 \%$. He is a Coinvestigator on Solar Radiation and Climate Experiment and the Instrument Scientist of the TIM currently flying on that mission and the TIM Instrument Scientist for both the NOAA Total Solar Irradiance Sensor and Total Solar Irradiance Calibration Transfer Experiment missions. He is the PI for the HySICS balloon flight instrument funded under a 2010 ESTO Instrument Incubator Program (IIP) and for a 2007 IIP demonstrating a novel solar cross-calibration approach currently baselined for CLARREO radiometric measurements.

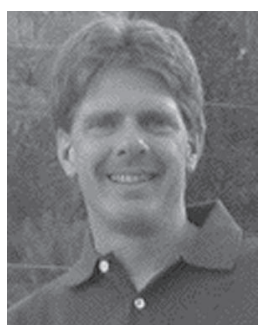

Kurt Thome received the B.S. degree in meteorology from Texas A\&M University, College Station, TX, USA, and the M.S. and Ph.D. degrees in atmospheric sciences from The University of Arizona, Tucson, AZ, USA.

He then joined what is now the College of Optical Sciences of the University of Arizona, where he became a Full Professor in 2006 and served as the Director of the Remote Sensing Group from 1997 to 2008. In 2008, he moved to NASA Goddard Space Flight Center, Greenbelt, MD, USA, as a Physical Scientist in the Biospheric Sciences Branch. He has been a member of the Landsat-7, ASTER, MODIS, and EO-1 Science Teams, providing vicarious calibration results for those and other imaging sensors. He is the Instrument Scientist for the Visible Infrared Imaging Radiometer Suite on the Joint Polar Satellite System and is serving as the Calibration Lead for the Thermal Infrared Sensor on the Landsat Data Continuity Mission. He is the Deputy Project Scientist for the Climate Absolute Radiance and Refractivity Observatory mission, for which he is also the Instrument Lead for the Reflected Solar Instrument.

Dr. Thome is a Fellow of The International Society for Optical Engineers.

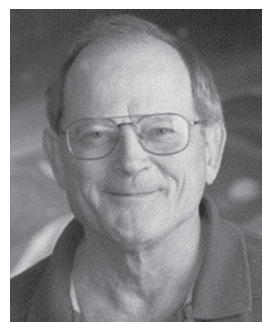

Bruce A. Wielicki received the B.S. degree in applied math and engineering physics from the University of Wisconsin-Madison, Madison, WI, USA, in 1974 and the Ph.D. degree in physical oceanography from Scripps Institution of Oceanography, La Jolla, CA, USA, in 1980.

Throughout his career, he has pursued extensive theoretical radiative transfer studies of the effects of nonplanar cloud geometry on the calculation of radiative fluxes, as well as on the retrieval of cloud properties and top-of-atmosphere radiative fluxes from space-based observations. He currently serves as the Principal Investigator on the NASA Climate Absolute Radiance and Refractivity Observatory mission with NASA Langley Research Center, Hampton, VA, USA. His research has focused on clouds and their role in the Earth's radiative energy balance for over 30 years, for which he has been a Coinvestigator on the Earth Radiation Budget Experiment, a Principal Investigator on the First International Satellite Cloud Climatology Experiment Project Regional Experiment (FIRE), a Principal Investigator on the Clouds and Earth's Radiant Energy System, and a Coinvestigator on the NASA Cloudsat and Cloud-Aerosol Lidar and Infrared Pathfinder Satellite Observations missions. He was a FIRE Project Scientist from 1987 to 1994.

Dr. Wielicki was a recipient of the NASA Exceptional Scientific Achievement Award in 1992 and the Henry G. Houghton Award from the American Meteorological Society in 1995.

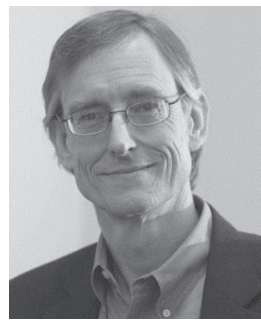

David F. Young received the B.S. degree in astrophysics from Michigan State University, East Lansing, in 1977 and the M.S. degree in meteorology from Pennsylvania State University, University Park, in 1979.

$\mathrm{He}$ is currently a Senior Scientist with the NASA Langley Research Center, Hampton, VA, USA, where he has been working for over 30 years to help in understanding the Earth's climate. He is currently the Director of the NASA Langley Science Directorate. Previously, he served as the Project Scientist for the Climate Absolute Radiance And Refractivity Observatory mission, which is a new NASA satellite mission aimed at providing the most accurate record to date of the Earth's evolving climate. In this position, he was responsible for leading an interagency international government/industry/university science team that is developing a mission to provide data with the accuracy needed to detect, understand, and improve the prediction of climate change for sound policy decisions. He has authored or coauthored 45 peer-reviewed science publications. His main areas of research include satellite remote sensing of cloud microphysical and radiation parameters and the development of data fusion techniques for the generation of climate data records. 